most patients with acromegaly GH levels fall. ${ }^{20} 21$ Again, levodopa was shown to have too short an action, and single doses of bromocriptine in acromegalic patients were found to lower GH levels. ${ }^{22}$ Patients have been treated successfully for up to nine months in the reports published so far. ${ }^{23-25}$ Higher doses are required than have been used for hyperprolactinaemia, usually between 20 and $60 \mathrm{mg}$ per day. The results of this medical treatment are encouraging: many patients have clinical, biochemical, and metabolic improvement. Since surgery and radiotherapy are often ineffective in reversing these manifestations bromocriptine will be a major therapeutic advance if its current promise is upheld.

Another obvious indication for bromocriptine is in treating Parkinsonism. There are theoretical advantages in the use of a dopamine agonist which, unlike levodopa, does not require to be metabolised to the active compound by dopaminergic neurones. All the reports indicate that bromocriptine may be superior to levodopa, though the results are not as dramatic as might have been expected on theoretical grounds. ${ }^{26-28}$

The side effects of bromocriptine are important. They may be divided into those which occur at the start of treatment and those found when patients are established on high doses. Any patient given a sufficiently large initial dose may develop nausea, vomiting, and postural hypotension. Micturition syncope has also been described. Normal people are the most sensitive to these initiating side effects; patients with hyperprolactinaemia and acromegaly less so; and finally the most resistant are women immediately post partum, in whom side effects are virtually unknown. Side effects may, however, usually be avoided if a really small dose is given at the start of treatment and then increased very slowly. Preferably treatment should be started in the evening, the dose being taken with food when going to bed.

The other side effects, found during continuous therapy, are rare when the daily dose is less than $20 \mathrm{mg}$ : they include mild constipation, muzziness, nasal congestion, cramps in the legs at night, and dystonic reactions in the Parkinsonian patients. Cardiac dysrhythmias have also occurred occasionally when high doses were given.

Probably in the future new ergot derivatives with even more specific effects will be found. Bromocriptine is likely to be the first of a new class of therapeutic agents-the dopamine receptor agonists-for which further indications will be found as the role of dopamine in the peripheral autonomic nervous system is delineated. ${ }^{29}$

${ }^{1}$ Symposium Ergot Compounds-The Changing Scene, Proceedings to be published in Postgraduate Medical fournal.

2 Barger, G, Carr, F H, and Dale, H, British Medical fournal, 1906, 2, 1792

3 Dodart, M, Fournal des Savants, 1676, p 76.

4 Shelesnyak, M C, Recent Progress in Hormone Research, 1957, 13, 269.

5 Shelesnyak, M C, Acta Endocrinologica, 1958, 27, 99.

6 Zeilmaker, G H, and Carlsen, R A, Acta Endocrinologica, 1962, 41, 321.

7 Flückiger, E, and Wagner, H R, Experientia, 1968, 24, 1130.

${ }^{8}$ Pasteels, J L, et al, Annales d'Endocrinologie (Paris), 1971, 32, 188.

${ }^{9}$ Besser, G M, et al, British Medical fournal, 1972, 3, 669.

10 Del Pozo, E, et al, fournal of Clinical Endocrinology and Metabolism, 1974, 39, 18.

11 Thorner, M O, et al, British Medical fournal, 1974, 2, 419.

12 McNatty, K P, Sawers, R S, and McNeilly, A S, Nature, 1974, 250, 653.

13 Zarate, A, et al, American fournal of Obstetrics and Gynecology, 1972, 112, 1130 .

14 Thorner, M O, et al, British Medical fournal, 1975, 4, 694.

15 Varga, L, et al, British Medical fournal, 1972, 2, 743.

${ }^{16}$ Rolland, R, and Schellekens, L A, Fournal of Obstetrics and Gynaecology of the British Commonwealth, 1973, 80, 945.

17 Hökfelt, T, and Fuxe, K, Neuroendocrinology, 1972, 9, 100.

18 Schally, A V, et al, Federation Proceedings, 1974, 33, 237.

19 Takahara, J, Arimura, A, and Schally, A V, Endocrinology, 1974, 95, 462.

${ }^{20}$ Liuzzi, A, et al, fournal of Clinical Endocrinology and Metabolism, 1972 $35,941$.
21 Camanni, F, et al, fournal of Clinical Endocrinology and Metabolism, 1975, 40, 363.

${ }^{22}$ Liuzzi, A, et al, fournal of Clinical Endocrinology and Metabolism, 1974, 38,910 .

23 Thorner, M O, et al, British Medical fournal, 1975, 1, 299.

${ }^{24}$ Chiodini, P G, et al, fournal of Clinical Endocrinology and Metabolism, 1975, 40, 705.

${ }^{25}$ Thorner, M O, et al, Abstract 125, Proceedings of 75th Annual Meeting of the Endocrine Society, 1975.

${ }^{26}$ Calne, D B, et al, British Medical fournal, 1974, 4, 442.

${ }^{27}$ Calne, D B, et al, Lancet, 1974, 2, 1355.

28 Teychenne, P S, et al, Lancet, 1975, 2, 473.

29 Thorner, M O, Lancet, 1975, 1, 662.

\section{Acute appendicitis in pregnancy}

"The mortality of appendicitis complicating pregnancy and the puerperium is the mortality of delay," wrote Babler ${ }^{1}$ in 1908, when he found a $49 \%$ mortality among 103 pregnant women with perforated appendicitis. We now have the means to salvage many more patients-in 1967-9 in England and Wales ${ }^{2}$ only two women died from acute appendicitis during pregnancy-but we still make too many late diagnoses and see some gravely ill patients. From 1950 to 1973 the incidence of gangrene and perforation of the appendix in pregnant women in $\mathrm{Oxford}^{3}$ was twice that among the non-pregnant, while in the same series two out of four fetal deaths occurred in mothers who had been treated conservatively in hospital for two and a half and for three days. Similar figures were reported from Melbourne ${ }^{4}$ in 1972, where the incidence of perforation in the last trimester was five times that in the first.

The clinical picture of acute appendicitis is in fact little changed in the first three or four months of pregnancy. It is especially in the last trimester and the puerperium that difficulties arise and delay in diagnosis may occur. What can be done to improve the situation?

There may be an understandable tendency for obstetricians to look for obstetric causes when acute abdominal pain occurs in their patients, but they must not overlook the fairly uncommon but dangerous surgical complications of pregnancy and the puerperium. A report from Aberdeen on some difficult cases appear at page 691 of this issue. The symptoms and signs of acute appendicitis (and other surgical emergencies) are considerably modified during late pregnancy and the puerperium. Parker, ${ }^{5}$ in a paper which should be read by all obstetricians and general surgeons, identified these differences. There may be a classical shift of pain, but often pain is only vaguely localised. Tenderness will be found over the appendix, but it is likely to be higher than usual and may be situated under the right costal margin or out in the right flank. In particular, muscle guarding tends to be slight or wholly absent, and this may mislead the examiner into underestimating the significance of local tenderness. The useful sign of altered tenderness described by Alders ${ }^{6}$ will help to differentiate uterine from extrauterine lesions, and the "heel-stamping" sign ${ }^{7}$ may alert the examiner to the presence of peritoneal irritation. Acute pyelitis may be a problem in differential diagnosis, but it is unwise to accept (as too often happens) that a few pus cells in the urine confirm a diagnosis of pyelitis. The Aberdeen paper stresses that anything more than intermittent mild colicky lower abdominal pain is abnormal in the puerperium.

In these diagnostic difficulties there is a natural unwillingnass to risk disturbing the pregnancy or the involuting uterus by 
a negative laparotomy, though the risk to the mother has been shown to be negligible and to the fetus very slight. ${ }^{8}{ }^{9}$ In fact, nothing disturbs the fetus so much as appendicitis progressing to peritonitis. Once the doctor appreciates that serious disorders may lurk behind seemingly mild signs it is essential to look critically at what symptoms and signs there are. If after a short period of "active observation"10 the surgeon is still unable to exclude acute appendicitis, then he must for safety's sake make a muscle-splitting incision ${ }^{511}$ over the point of maximum tenderness. In acute appendicitis, even in advanced pregnancy, this approach will provide good exposure of the appendix and cause the minimum of uterine disturbance. When in doubt the surgeon must look and see, not wait and see.

\footnotetext{
1 Babler, E A, fournal of American Medical Association, 1908, 51, 1310.

2 Department of Health and Social Security. Reports on Health and Social Subjects, No 1, p 95. London, HMSO 1972.

${ }^{3}$ Finch, D R A, and Lee, E, British fournal of Surgery, 1974, 61, 129.

4 Taylor, J D, Australian and New Zealand fournal of Obstetrics and Gynaecology, 1972, 12, 202.

5 Parker, R B, Lancet, 1954, 1, 1252.

6 Alders, N, British Medical fournal, 1952, 2, 1194.

${ }^{7}$ Rösemann, G W E, South African Medical fournal, 1975, 49, 1459.

${ }^{8}$ O'Neill, J P, Australian and New Zealand Fournal of Obstetrics and Gynaecology, 1969, 9, 94.

9 Saunders, P, and Milton, P J D, British Medical fournal, 1973, 3, 165.

10 Jones, P F, Lancet, 1975, 2, 546.

11 McCorriston, C C, American fournal of Obstetrics and Gynecology, $1963,86,593$.
}

\section{Salmonellas in sausages}

Between 1969 and 1974 workers in the Public Health Laboratory Service (PHLS) examined 3309 samples from packets of pork sausages produced by two large and two medium-sized manufacturers and by several local butchers. Of these, 786 samples were found to contain salmonellas. ${ }^{1}$ Almost all $(95 \%)$ of these isolations came from the products of one large manufacturer; salmonellas were not isolated from any of the butchers' sausages; and the packets of the two medium-sized manufacturers yielded $4 \%$ and $11 \%$ of isolations respectively. The incidence of salmonellas in the samples of the other large manufacturer was consistently low, ranging between $1 \cdot 1 \%$ and $3.7 \%$ of packets. Samples from a source containing sulphite as preservative more often yielded salmonellas than did samples from two sources not containing sulphite, but the number of observations on this point was low-only 312 packets were examined.

What practical conclusions may be drawn from these results ? The total figure of $29.7 \%$ of packets yielding salmonellas is not substantially different from those reported by three other groups of workers cited in the PHLS paper. At first sight the figure might suggest that British housewives would do well to avoid buying sausages until all manufacturers attain the standards of the best; but this conclusion would be wrong. Though many millions of sausages are eaten in Britain every day, sausages and sausage meat are relatively uncommon causes of salmonella food poisoning. Sausages were implicated in only ten food-poisoning outbreaks from 1967 to 1972. The PHLS paper does not include information about the numbers of salmonellas found in the sausages, only about the proportion of samples found to be positive, and the number of these bacteria needed to produce the clinical signs and symptoms of food poisoning is known to be high. Even in sausages which are contaminated with salmonellas the number may be kept low by the preservative even if it does not significantly reduce the number of samples containing salmonellas. Moreover, in Britain sausages are normally fried, grilled, or baked at temperatures which will still further reduce the number of any salmonellas present. All of this accords with the observation that, compared with other known sources of salmonella food poisoning, sausages come low on the list. To help keep them low on it some practical advice on cooking sausage-meat stuffing for the Christmas turkey is given by Dr N D Noah in our epidemiology columns this week.

For microbiologists the PHLS paper shows the interesting facts that incubation of enrichment cultures at $43^{\circ} \mathrm{C}$ yielded a consistently greater number of salmonella isolations than at $37^{\circ} \mathrm{C}$, regardless of plating medium; that tetrathionate broth A (Rolfe) ${ }^{3}$ was superior to selenite broth as an enrichment medium at both $37^{\circ}$ and $43^{\circ} \mathrm{C}$; and that brilliant green agar gave better results than deoxycholate citrate sucrose agar and bismuth sulphite agar as a selective medium.

The wider importance of these results is what they allow us to infer about salmonellas in pig meat at its source-and thus about the best methods of preventing their appearance in the finished product. The wide difference in the incidence of salmonellas between the products of the two large manufacturers suggests the probability that one could choose his meat from selected pigs, carefully fed and managed up to the time of slaughter, whereas the other may have been taking his supplies from many sources. Pigs that are fed on swill, badly transported to slaughter, or accommodated in dirty lairages are much more likely to produce contaminated carcasses than pigs fed on clean food and properly managed up to and after slaughter. It would have been interesting to know whether such influences could explain the wide difference observed. There is a hint in the discussion that this is the most likely explanation. With the coming into force of the Zoonoses Order ${ }^{2}$ in July 1975 it will now be much easier than before to identify and trace back to source the true origins of salmonella food poisoning. Good management of hygiene in the food-processing factory is also vital, and the results suggest the possibility that it may be easier for a small firm to secure good discipline from its staff than for a large one.

1 Roberts, D, et al, fournal of Hygiene, 1975, 75, 173.

2 Statutory Instrument 1975 No 1030, The Zoonoses Order. London, HMSO, 1975.

${ }^{3}$ Rolfe, V, Monthly Bulletin Ministry of Health and Public Health Laboratory Service, 1946, 5, 158.

\section{Hazards of tabes dorsalis}

Tabes dorsalis has become uncommon in Britain to the point of rarity. The Chief Medical Officer of the Department of Health and Social Security reported ${ }^{1}$ that in 1973 only 144 cases of neurosyphilis of all kinds were treated at venereal disease clinics in England, and the number of recorded deaths from tabes was only 15. This form of the disease presents at a time remote from the onset of syphilis and often with symptoms and signs far from typical. Undoubtedly some cases are seen in hospital departments where awareness of the nature of the condition and its management may seem to be lacking. Ghosh and Holt. ${ }^{2}$ reported the case of a man who in 1962 